\title{
Gestão Democrática Participativa: Estudo de Caso no Conselho Escolar da Escola de Ensino Médio Barão de Aracati no período de 2012 a 2014
}

\author{
Adriana Pinto Lima ${ }^{1}$; Juan Pablo Wieschollek Acosta ${ }^{2}$
}

\begin{abstract}
Resumo: Com o intuito de refletir sobre a Gestão Democrática Participativa, estabelecendo uma análise minuciosa sobre os aspectos mais relevantes dessa nova forma de gerir as escolas em consonância com o processo de construção de uma sociedade mais democrática de participativa, o presente trabalho centra a sua atenção na atuação do Conselho Escolar da Escola de Ensino Médio Barão de Aracati, por entender que este colegiado traz em si mesmo a essência da Gestão Democrática Participativa, pois agrega em sua composição a representação da comunidade que tem como principais funções: consultar, deliberar, normatizar, fiscalizar e avaliar todos os assuntos que envolvem a instituição, pedagógico, financeiro e administrativo. Assim, a pesquisa objetiva estabelecer os graus de participação do colegiado, identificando os avanços e possíveis obstáculos para a implantação da Gestão Democrática.
\end{abstract}

Palavras - chave: Gestão Democrática Participativa; Conselho Escolar; comunidade escolar.

\section{Participative Democratic Management: Case Study School Council at the Barão de Aracati High School from 2012 to 2014.}

\begin{abstract}
In order to reflect on Participatory Democratic Management, establishing a detailed analysis of the most relevant aspects of this new way of managing schools in line with the process of building a more democratic participatory society, this paper focuses on attention in the performance of the School Council of the Barão de Aracati High School, because it understands that this collegiate has in itself the essence of Participative Democratic Management, since it adds in its composition the representation of the community whose main functions are: consulting, deliberating, standardize, supervise and evaluate all matters involving the institution, pedagogical, financial and administrative. Thus, the research aims to establish the degrees of participation of the collegiate, identifying the advances and possible obstacles to the implementation of Democratic Management.
\end{abstract}

Keywords: Participatory Democratic Management; School Council; school community.

\section{Introdução}

A trajetória da educação brasileira desde o sistema colonial até os dias atuais é repleta de altos e baixos, que refletiram e refletem nos resultados da aprendizagem da sociedade. Durante muito tempo, a educação era privilégio de uma minoria elitizada, que comandava o cenário político nacional, deixando o restante da sociedade à margem do processo educacional.

\footnotetext{
${ }^{1}$ Licenciatura em História pela Universidade Estadual do Rio Grande do Norte (1998). Tem especialização em Psicopedagogia pela Universidade do vale do Acaraú e especialização em Gestão Escolar pela Universidade do estado de Santa Catarina. Atualmente é professora da Universidade Estadual Vale do Acaraú e professora do Instituto Waldemar Falcão. Mestre em Educação pela Universidade de Santiago de Chile. Contato: adrianapintocoordenadora@ gmail.com.

${ }^{2}$ Orientador do Curso de Mestrado em Educação. Faculdade de Humanidades da Universidade de Santiago de Chile
} 
Com a redemocratização do país, a educação toma um novo rumo e finalmente é estabelecida uma política educacional com o objetivo de ofertar um ensino público de qualidade com equidade para todos os cidadãos brasileiros. Atingir esse propósito configura-se em um dos maiores desafios já estabelecidos pelo governo brasileiro ao longo de toda a história da educação.

Em uma gestão democrática, a equipe gestora, principalmente o diretor, assume um papel fundamental no sentido de estabelecer os caminhos para a participação de todos os envolvidos, direta ou indiretamente, no processo de ensino-aprendizagem da instituição. Portanto, a equipe gestora deve ter clareza de sua função, exigindo, muitas vezes, uma mudança de postura, uma vez que a concepção de gestão é diferente do que se acreditava há uns anos atrás como tarefa do diretor (ALVES e MOURA, 2013).

Assim, ao fazer uma análise sobre a Gestão Democrática Participativa, verificou-se que o Conselho Escolar é um órgão de vital importância para o fortalecimento da participação da comunidade educativa na condução do processo pedagógico, financeiro e administrativo das escolas. Nesta perspectiva, o presente trabalho intitulado "Gestão Democrática Participativa: Caso de estudo Conselho Escolar na Escola de Ensino Médio Barão de Aracati no período de 2012 a 2014.", busca uma análise profunda sobre o funcionamento do Conselho Escolar tendo por objetivo detectar o grau de participação do Conselho Escolar da Escola de Ensino Médio Barão de Aracati, no período de 2012 a 2014, descrevendo o significado da Gestão Democrática Participativa para os conselheiros e comparando sua atuação com o que propõe a Secretaria de Educação do Estado do Ceará para o colegiado. Obtendo-se todas as informações necessárias e após analisá-las minuciosamente, o presente trabalho objetiva propor orientações para tornar a gestão da escola mais democrática e participativa, com um conselho mais atuante e eficaz.

Alcançar a Gestão Democrática e Participativa é um objetivo presente no cenário educacional brasileiro desde a Constituição de 1988 e a elaboração da Lei de Diretrizes e Bases da Educação - LDB de 1996. Desde esse período que o Estado do Ceará vem tomando medidas, estabelecendo convênios e implantando projetos para a concretização desse objetivo nas escolas públicas do estado. No município de Aracati, no interior do estado, a Escola de Ensino Médio Barão de Aracati, presente na cidade a mais de oitenta anos, vem vivenciando as mudanças ocorridas em prol da democratização do ensino, procurando oferecer uma educação de qualidade para os jovens da localidade. 
Como uma das instituições públicas de ensino mais antiga da cidade, a Escola Barão de Aracati passou por inúmeras gestões ao longo de sua história, sendo que nos últimos dez anos vivencia o processo da Gestão Democrática. Portanto, é de fundamental importância uma investigação sobre a implantação da Gestão Democrática Participativa através da atuação do Conselho Escolar, compreendendo o nível de participação de seus integrantes e a contribuição destes para a implantação dos princípios democráticos na escola.

Em síntese o problema a ser investigado é "Qual o grau de participação do Conselho Escolar no processo de gestão democrática da Escola Barão de Aracati no período de 2012 a 2014?”. Tal investigação pretende compreender como o Conselho Escolar vem atuando na referida escola, identificando e analisando os avanços e os obstáculos na participação e construção da Gestão Democrática Participativa.

O objetivo principal do presente estudo foi analisar o grau de participação do Conselho Escolar no processo de gestão democrática participativa na Escola de Ensino Médio Barão de Aracati no período de 2012 a 2014. Para isso foi necessário também: a) Descrever o significado da Gestão Democrática Participativa para o Conselho Escolar da Escola de Ensino Médio Barão de Aracati de 2012 a 2014; b) Comparar a atuação do Conselho Escolar da Escola de Ensino Médio Barão de Aracati com o que propõe o plano de governo do Estado do Ceará para este colegiado; e, c) Propor orientações para tornar a Gestão Democrática da Escola de Ensino Médio Barão de Aracati mais efetiva e eficaz, através da atuação do Conselho Escolar.

\section{Planejamento Participativo: princípio da Gestão Democrática}

O planejamento participativo no processo de Gestão Democrática é fundamental para garantir a participação plena da comunidade educativa. Quando todos que compõem a escola participam do planejamento das ações começam a desenvolver um senso de corresponsabilidade e a consciência de seu dever em contribuir para o objetivo maior da educação, a aprendizagem de seus alunos (LUCK, 2011).

No momento em que as decisões são impostas, sem a participação da comunidade educativa, é natural um sentimento de impotência e até mesmo de comodismo perante os rumos estabelecidos. As reações podem ser inúmeras, desde a compreensão e concordância com o que foi determinado, como a revolta e negação daquilo que foi imposto, levando ao conflito e consequentemente ao fracasso. 
Para que a situação citada não ocorra, o gestor tem um papel essencial ao promover os espaços necessários para que todos participem do processo de construção do ensino aprendizagem da escola, definindo em conjunto qual o planejamento que melhor atende ao modelo de gestão que se quer implantar.

Um gestor deve escolher o tipo de planejamento que deseja exercer em sua instituição de ensino e incorporar ao mesmo as características do planejamento participativo.

O planejamento é um caminho fundamental para um processo de mudanças, para criar as condições necessárias para alcançar os objetivos traçados e interferir na realidade. Assim, o gestor estará exercendo a sua função política. Para ANDRADE (2012),

\begin{abstract}
"A partir da democratização das decisões, o gestor estará dando um grande passo positivo para que a função dele seja repensada e até mesmo aperfeiçoada, porque no momento em que ele permite que a comunidade dê sua opinião e avalie os resultados de um processo que resulta, em parte, da sua atuação, muitos fatores positivos para o seu desenvolvimento profissional serão necessários para que o mesmo assuma uma postura revolucionária, repensando que tipo de homem deseja que a escola forme, para que assim, os alunos sejam inseridos num contexto social mais amplo. Esta é a dimensão política da função do gestor.” ANDRADE, 2012 p-6.
\end{abstract}

A implantação da gestão democrática não é tarefa fácil, pois a mesma necessita de uma série de ações complexas que o gestor deve executar. $\mathrm{O}$ diretor precisa conhecer a escola profundamente, ter clareza de sua função social, dos caminhos necessários para alcançar as metas propostas e saber conduzir a equipe escolar para atingir com êxito a aprendizagem de seus alunos.

O planejamento participativo é uma prática muito importante para o processo de gestão democrática, pois permite que todos que compõem a comunidade educativa, professores, pais, alunos, funcionários e equipe gestora, participem das etapas do planejamento voltado para transformações significativas no interior da escola. Sobre esse aspecto MEDEL (2008) diz, “(...), a gestão democrática entende que todos os envolvidos no trabalho escolar não devem apenas saber como a escola funciona, mas também participar na definição dos seus rumos. Nesse sentido, a escola não pode centrar o seu trabalho na figura dos gestores, mas abrir-se à participação de todos nas decisões (...) p-53".

Outro aspecto que o planejamento participativo deixa evidente é o da autonomia.

"O princípio da autonomia relaciona-se diretamente ao da qualidade de ensino para todas as escolas. Elas necessitam garantir um padrão mínimo de qualidade para todos os alunos e para todas as escolas do sistema. A busca da qualidade pressupõe também o princípio da gestão democrática como orientador da construção de uma escola que 
valorize as relações estabelecidas pelos indivíduos em seu cotidiano.” MEDEL, 2008 p-54.

Assim, a autonomia não significa tomar decisões à revelia do que o sistema educacional determina, mas, a partir das orientações construírem a identidade da escola, seus princípios e metas para alcançar a qualidade do ensino. O gestor deve ficar atento para exercer a sua liderança, não tomando as decisões sozinho e arcando com todas as responsabilidades, mas, proporcionando momentos em que todos possam ser corresponsáveis pelas decisões.

Sobre a autonomia da escola LUCK (2012) argumenta,

\footnotetext{
"O conceito de autonomia da escola está relacionado a tendências mundiais de globalização e mudança de paradigma que têm repercussões significativas nas concepções de gestão educacional e nas ações dela decorrentes. Descentralização do poder, democratização do ensino, autogestão, instituição de parcerias, flexibilização de experiências, sistema de cooperativas, multidisciplinaridade são alguns dos conceitos relacionados a essa mudança. Entende-se como fundamental, nesse conjunto de concepções, a mobilização de massa crítica devidamente capacitada, para se promover a transformação e sedimentação de novos referenciais de gestão educacional" (p-62).
}

Quando se fala em autonomia da escola, alguns cuidados devem ser tomados. A autonomia não é sinônimo de "soberania", no sentido pejorativo da palavra, onde cada um faz o quem bem quer, sem regras, sem liderança. Pelo contrário, autonomia na escola é um processo orientado, incorporado por todos, realizado no dia a dia da instituição, voltado para a concretização de um sonho comum.

Um aspecto extremamente relevante da gestão democrática e que foi citado por Veiga, é a prática da avaliação das ações projetadas. O núcleo gestor deve ficar atento para promover momentos de avaliação da prática pedagógica, pois, é avaliando que se tem clareza se os objetivos estão sendo alcançados e se há necessidade de redimensionamentos. Segundo VASCONCELOS (2005), “a avaliação é um processo abrangente da existência humana, que implica uma reflexão crítica sobre a prática, no sentido de captar seus avanços, suas resistências, suas dificuldades e possibilitar uma tomada de decisão sobre o que fazer para superar os obstáculos.” (p-43). Portanto, uma equipe pedagógica que avalia constantemente o seu trabalho, cria bases sólidas para a construção de uma escola eficiente e eficaz. 


\section{Metodologia de Estudo}

A pesquisa propôs-se a um estudo de caso com integrantes do Conselho na Escola de Ensino Médio Barão de Aracati, no período de 2012 a 2014, dentro do processo de Gestão Democrática Participativa.

As informações foram coletadas através de entrevista semiestruturada aplicada a todos os membros do Conselho Escolar, objetivando detectar o grau de participação dos mesmos na gestão da escola.

Após a aplicação da entrevista, cada pergunta com as devidas respostas foram transcritas na integra e confrontadas entre si e com o que determina as diretrizes do Ministério da Educação e Secretaria de Educação do Estado do Ceará para a organização e atuação dos Conselhos Escolares no estado e no país, trazendo também para uma reflexão o que se espera de uma Gestão Democrática Participativa, segundo teóricos da educação, com o que se detectou na escola em estudo.

\section{Resultados}

Sobre a função deliberativa, o primeiro questionamento foi: O Conselho Escolar participa e acompanha a aplicação do Projeto Político Pedagógico da instituição? Em que aspectos há participação?

\footnotetext{
Conselheiro 1: Participa na elaboração dando opiniões. Mas, não acompanha a aplicação. Conselheiro 2: Bom. Em relação ao conselho escolar eu posso dizer assim, que ele de fato participa, participou na elaboração dentro da formação de cada segmento. Dizer que ele acompanha, isso não acontece, esse acompanhamento sistemático, ele não acontece. Bom, eu acredito assim, o próprio sistema se encarrega de não ter disponibilidade, por questão do tempo, existe assim, outras, que isso é uma prioridade. Mas, existem tantas situações dentro da própria escola que, enquanto gestor, enquanto conselho, a gente não utiliza esse tempo, porque não é permitido. Porque esse conselho é formado por professores, que estão em sala de aula, pela pessoal de serviços gerais, que também está na sua função, que não dá nem conta do que tem pra ser feito. Então assim, é próprio sistema que não possibilita que isso venha a ocorrer, não é porque ele não se permite. A própria gestão da escola ela não tem tempo pra ter esse acompanhamento, juntamente com o conselho.

Conselheiro 3: Sempre acompanha, quando a pessoa precisa o conselho escolar em qualquer momento, toda hora tem que tá junto, como o povo da escola, no que tá precisando sempre. Conselheiro 4: A participação do Conselho Escolar na aplicação do Projeto Pedagógico de nossa escola é mínima. Na verdade ele participa da elaboração porque é convocado, porém sua atuação no desenvolvimento se restringe à participação dos professores conselheiros nas atividades cotidianas da Instituição.
} 
Conselheiro 5: Sim, o Conselho Escolar participa da elaboração do PPP da escola, quando nos reunimos com outros segmentos para responder algumas questões. Quanto ao acompanhamento sempre que somos convocados para reuniões sobre esse assunto nos fazemos presentes.

Conselheiro 6: Sim. Principalmente ao que tange aos aspectos financeiros, porque no ambiente escolar carece muito do conhecimento financeiro, administrativo-financeiro, até para a melhoria da qualidade do ensino. Dentro do meio escolar, necessitam um bom gerenciamento e uma boa locação de recursos.

Conselheiro 7: Sim, porém não tenho conhecimento sobre tal.

Conselheiro 8: Não. Não há interesse em participar.

Conselheiro 9: No início do ano letivo, durante a semana pedagógica o PPP é avaliado, são traçadas metas. Mas, durante o decorrer do ano não há este acompanhamento que fica a cargo da equipe pedagógica.

Conselheiro 10: No começo do ano somos chamados e nos é apresentado o PPP. Mas depois não acompanhamos se é aplicado.

Com relação à participação na elaboração do Projeto Político Pedagógico, observa-se que a maioria dos conselheiros afirmam ter participado da elaboração do documento mas, em relação ao acompanhamento das ações definidas pelo projeto, é quase unânime a afirmação de que não há este acompanhamento. Isto demonstra que o Conselho Escolar não percebe a importância do Projeto Político Pedagógico e que a implantação do mesmo é essencial para garantir o sucesso da instituição. A não participação do Conselho Escolar fragiliza a aplicação do projeto, uma vez que, por se tratar de um documento fundamental, que estabelece a filosofia da escola, seu objetivo, suas metas, é importante que este de fato seja aplicado e o Conselho ao acompanhar de perto as ações, pode apontar falhas, propor sugestões e discutir soluções, transformando-o em um instrumento vivo no interior da instituição. Sobre este aspecto, o Ministério de Educação orienta,

\begin{abstract}
“(...) é fundamental que a escola tenha a sua "filosofia político-pedagógica norteadora”, resultante, como já mencionado, de uma análise crítica da realidade nacional e local e expressa em um projeto político-pedagógico que a caracterize em sua singularidade, permitindo um acompanhamento e avaliação contínuos por parte de todos os participantes das comunidades escolar (estudantes, pais, professores, funcionários e direção) e local (entidades e organizações da sociedade civil identificadas com o projeto da Escola)." PROGRAMA NACIONAL DE FORTALECIMENTO DOS CONSELHOS ESCOLARES-CADERNO 1, 2004, pp. 24
\end{abstract}

A ausência de acompanhamento da implantação do Projeto Político Pedagógico pelo Conselho Escolar, pode ter a sua origem na falta de conhecimento da função dos conselheiros na escola, na ausência de reuniões do colegiado para estudo das competências do mesmo, o que fragiliza as ações dos seus componentes. Como foi explicitado acima, o Ministério de Educação defende e orienta que, o Projeto Político Pedagógico das escolas, deve ser do conhecimento de toda a comunidade educativa e que o mesmo, deve ser acompanhado e avaliado regularmente 
pela comunidade, para que a função social da Educação Básica (formar cidadãos), seja de fato garantida.

A segunda pergunta da entrevista, ainda dentro da temática da função deliberativa do Conselho Escolar, investiga a seguinte situação: O Conselho Escolar acompanha os planejamentos das ações pedagógicas da escola e propõe intervenções? Exemplifique uma situação vivenciada.

\footnotetext{
Conselheiro 1: Não. Quando chega a verba é convocada uma reunião pra os que estão à frente dizerem as prioridades e a gente assinar a ata. Reunião de professor a gente não participa não.

Conselheiro 2: Não. É exatamente ela com a mesma resposta da primeira. Pelo fato de que assim, o acompanhamento pedagógico não. Isso só se dá com o grupo pedagógico, com os PCAs, com a direção, a gente tem uma avaliação geral, num determinado momento em que o conselho está reunido, que passa. Mas, isso não é sistemático.

Conselheiro 3: Acompanha. Que quando tem quando tem uma coisa errada dentro da escola, o conselho escolar chega junto com o povo, com o grupo gestor, aí sempre dá certo, né? Conselheiro 4: Na verdade, temos um Conselho Escolar atualmente pouco participativo, comparecendo às reuniões somente quando são convocados pelo Núcleo Gestor da Escola. Acredito que por falta de conhecimento e por não querer assumir a responsabilidade pelas atribuições que lhe são cabiveis.

Conselheiro 5: Durante as reuniões do CE algumas tinham como pauta ações pedagógicas, tais como as relacionadas ao Calendário Escolar, realizações de eventos e o CE apontou sugestões.

Conselheiro 6: Sim. É função do conselho escolar o viés pedagógico e o viés financeiro. Ele acompanha todos os planejamentos das ações pedagógicas desenvolvidos na escola. Como exemplo, no que tange as ações comunitárias, fazer palestras envolvendo todos da comunidade, muito embora a gente note que não há uma participação como deveria ser, em determinadas palestras, em determinadas ações pedagógicas, que visem integrar escola a comunidade.

Conselheiro 7: Não sei informar, pois nunca participei d um planejamento dessa natureza. Conselheiro 8: Somente quando há problemas com aluno. Não participamos dos planejamentos com os professores.

Conselheiro 9: Não. O conselho se restringe aos assuntos financeiros da instituição.

Conselheiro 10: Não. Nunca participei de um planejamento.
}

Pode-se observar que a participação do Conselho Escolar em reuniões de planejamento para pensar as ações pedagógicas é praticamente inexistente. Alguns conselheiros afirmam que atuam apenas quando se trata de ações financeiras e outros dizem que nunca participaram de reuniões de planejamento e desconhecem a sua existência. Esses relatos apenas confirmam que, o Conselho Escolar da Escola de Ensino Médio Barão de Aracati não possui um conhecimento claro sobre a função deliberativa, fragilizando consideravelmente a implantação de uma Gestão Democrática Participativa na instituição. Quando não está consolidado o planejamento participativo das ações pedagógicas, administrativas ou financeiras, corre-se o risco de decisões isoladas, centralizadas na figura do diretor, comprometendo o trabalho coletivo, já que acaba 
prevalecendo a opinião unilateral, focada em um único ponto de vista. Assim, o planejamento participativo traz inúmeras vantagens para a instituição, que segundo GANDIN (2013) são,

\footnotetext{
“Compreender, cada vez mais, a realidade global na qual a entidade está incluída e para onde deve dirigir a busca de seus resultados;

Tornar, cada vez mais, precisos e claros seus horizontes, ou seja, seu ideal de fins e de meios;

Avaliar sua prática em relação a esses ideais;

Decidir suas novas práticas e atuar sobre a realidade concreta e próxima, em forma de ser e de agir, através de planos globais e setoriais, pelo menos de médio e de curto prazos." (p. 98)
}

O Ministério de Educação, através do Programa de Fortalecimento dos Conselhos Escolares, expõe de forma clara e precisa a importância do conhecimento e participação da comunidade educativa na construção do Projeto Político Pedagógico das escolas, bem como, do envolvimento das ações pedagógicas da mesma.

\begin{abstract}
“O projeto político-pedagógico elaborado apenas por especialistas não consegue representar os anseios da comunidade escolar, por isso ele deve ser entendido como um processo que inclui as discussões sobre a comunidade local, as prioridades e os objetivos de cada escola e os problemas que precisam ser superados, por meio da criação de práticas pedagógicas coletivas e da corresponsabilidade de todos os membros da comunidade escolar. Esse processo deve ser coordenado e acompanhado pelos Conselhos Escolares.” PROGRAMA NACIONAL DE FORTALECIMENTO DOS CONSELHOS ESCOLARES-CADERNO 1, 2004, pp. 33
\end{abstract}

Assim, ao se estabelecer um planejamento participativo, com a atuação de todos os segmentos da escola e principalmente, garantir a participação ativa do Conselho Escolar, a instituição estabelece em bases fortes o seu Projeto Político Pedagógico, fundamentando suas ações em direção a metas bem construídas e claras para todos da comunidade educativa, estabelecendo portanto, sua plena realização.

A segunda função do Conselho Escolar refere-se a função consultiva. Sobre esta atribuição do conselho foi estabelecida a seguinte pergunta: Em que situações o Conselho Escolar é convocado para tomada de decisões (pedagógica, financeira, administrativa)? As respostas dos conselheiros foram semelhantes, assim transcritas,

Conselheiro 1: Nenhuma. Que eu me recordo a gente nunca é chamado para tomar decisões. É chamado pra participar da reunião que tem pra assinar a ata. Decidir, opinar, as vezes acontecer da pessoa dar um sugestão mas, ...

Conselheiro 2: Na questão mais financeira, quando vem os recursos, a gente se reúne, pelo que eu percebi, isso é constante, quando vem os recursos, a gente senta, se reuni. A gente é convocado pra saber, já que os recursos são poucos, no que a gente pode aplicar. Então a 
gente vai de fato vai priorizar a prioridade, porque o dinheiro que tem não é suficiente para atender as necessidades da própria escola.

Conselheiro 3: Porque, quando tem assim, uma reunião, quando tem uma coisa dentro da escola, que tá precisando, aí se reúne o conselho, aí vamo olhá o que tá precisando dentro da escola.

Conselheiro 4: O Conselho Escolar é convocado para deliberação dos recursos financeiros, avaliação de professores em estágio probatório, decisões relacionadas a situações que envolvem a transferência ou remanejamento de alunos, realização de eleição de diretor e em outras ocasiões necessárias, garantindo a gestão democrática e participativa.

Conselheiro 5: Algumas decisões da escola são discutidas nas reuniões do CE. Na questão pedagógica, sobre decisões em relação a comportamento, conduta de alunos, quando somos convocados, financiamento, no direcionamento da aplicação de verbas que chegam à escola e no aspecto administrativo, quando decisões precisam ser tomadas somos convocados.

Conselheiro 6: Principalmente em decisões financeiras e administrativas. Não que a pedagógica não seja importante, mas, a gente já respira, vivencia os preceitos pedagógicos. O bom tempo, é muito bem gerido, cabendo muito mais as decisões administrativas $e$ as decisões financeiras, para que o conselho se debruce sobre esses aspectos.

Conselheiro 7: Geralmente no início do ano letivo, ou quando há uma decisão a ser tomada ou um projeto a realizar.

Conselheiro 8: Somente para assinar as atas das decisões e para prestação de contas.

Conselheiro 9: Quando chegam os recursos para a definição de sua aplicação e nas prestações de contas. Também somos convocados para decidir sobre a transferência de algum aluno indisciplinado.

Conselheiro 10: Quando é para discutir com o que comprar pra escola, ou quando algum aluno vai ser transferido.

De acordo com os relatos acima, observa-se que o Conselho Escolar, na maioria das vezes, reúne-se quando chegam recursos financeiros à escola. Geralmente, quem convoca as reuniões é o diretor da instituição, que também direciona a pauta a ser tratada. Segundo os depoimentos, percebe-se que, uma parte significativa dos conselheiros afirmam serem convocados apenas quando os recursos chegam ou quando ocorre algum problema disciplinar grave, que precisa do referendum dos conselheiros para tomar uma decisão definitiva sobre o destino de algum aluno. Portanto, essa falta de ação independente do conselho fica evidente, uma vez que o mesmo não apresenta uma prática de reuniões para acompanhamento, o que pode ser um fator determinante para a pouca participação no dia a dia da escola. Não se ter um conselho escolar atuante, torna o trabalho do diretor comprometido pois, ao tomar decisões sobre aspectos importantes de maneira solitária, pode levar a medidas errôneas e fracassadas.

Dando continuidade à função consultiva, os entrevistados foram indagados sobre a seguinte atuação: O Conselho Escolar exerce a função consultiva com frequência? Sendo este questionamento assim respondido, aconteça, a gente pode dizer, mas ela não tem essa frequência, não tem esse seguimento. 
Conselheiro 3: É sempre o conselho é chamado. Quando assim, tem um aluno tá pra terminar a escola, que ele não quer nada na vida, aí o conselho chega junto, que aquele aluno for bom na escola, aí a gente passa.

Conselheiro 4: Esta é a função que o Conselho Escolar exerce melhor, pois acontece através da convocação da Gestão para tomada de decisões.

Conselheiro 5: De acordo com as datas definidas em reuniões e também quando surgem as necessidades.

Conselheiro 6: Sim. Principalmente no que tange a questão das prioridades, relativos ao consumo, relativos a merenda escolar e relativos também a determinadas dotações orçamentárias.

Conselheiro 7: Não.

Conselheiro 8: Não.

Conselheiro 9: Somente quando necessário.

Conselheiro 10: Não. Raramente sou chamada.

De acordo com os relatos, existe algum ponto de divergência entre os conselheiros. Cinco conselheiros afirmam que o Conselho Escolar não exerce a função consultiva com frequência, ao passo que outros cinco afirmam que esta função acontece com mais frequência. Isso é contraditório, pois, a questão anterior mostra que os conselheiros se reúnem apenas quando chegam os recursos ou quando do diretor convoca para casos extraordinários. No que se refere aos recursos financeiros, estes não são muitos, o que deixa os conselheiros em uma situação de ociosidade e passividade diante da Gestão (Direção) da escola. Essa ausência de atitude dos conselheiros compromete a implantação da Gestão Democrática Participativa. Segundo ANTUNES (2002), o estabelecimento de uma ação mais participativa nos diversos aspectos da instituição, depende de se obter com maior clareza possível o que é a democracia.

"É necessário que tenhamos clareza de que democracia é algo que se aprende e se aprende, principalmente, praticando-a, vivenciando-a. Não há projeto de escola que esteja dissociado de um projeto de sociedade. Se queremos uma sociedade democrática, justa, igualitária, é necessário que, mais do que o discurso da democracia, sejamos capazes de vivenciar a democracia no maior número de espaços possível. (...)” ANTUNES, 2002, pp. 35.

Entende-se assim, que é necessário oportunizar mais momentos e espaços para a participação, estimulando a atuação e autonomia do Conselho Escolar e garantindo, de fato, que as decisões sejam tomadas de forma coletiva e o mais democrática possível.

Toda instituição educativa é regida por normas e leis, fundamentais para estabelecer a legalidade e transparência, essenciais em um estabelecimento de ensino, que tem como um dos princípios fundamentais a construção de um cidadão consciente de seus direitos e deveres e capaz de conviver em harmonia com seus pares.

"As atribuições do Conselho Escolar dependem das diretrizes do sistema de ensino e das definições das comunidades local e escolar. O importante é não perder de vista que o 
Regimento, a ser construído coletivamente na escola, constitui a referência legal básica para o funcionamento da unidade escolar e, desse modo, é fundamental que a instituição educativa tenha autonomia para elaborar seu próprio regimento. Dentre as principais atribuições do Conselho destacamos a sua função de coordenação do coletivo da escola e a criação de mecanismos de participação.” PROGRAMA NACIONAL DE FORTALECIMENTO DOS CONSELHOS ESCOLARES-CADERNO 5, 2004, pp. 45.

$\mathrm{O}$ conhecimento do regimento escolar, documento que contém todas as normas e diretrizes da instituição, que estabelece os direitos e deveres de professores, alunos, funcionários e núcleo gestor, bem como as normas de boa convivência entre todos da comunidade educativa e as penalidades caso tais regras sejam transgredidas, deve ser de conhecimento de todos que fazem parte da escola, pois, conhecer as leis é essencial para garantia da democracia. É responsabilidade do Núcleo Gestor e do Conselho Escolar conhecer e divulgar para pais, alunos, funcionários e professores as normas da instituição e zelar para que as mesmas sejam respeitadas e cumpridas.

No intuito de investigar se o Conselho Escolar tem conhecimento sobre a sua função normativa foi realizado o seguinte questionamento para seus membros: Você percebe se o Conselho Escolar tem conhecimento sobre o regimento da escola? Obteve-se como respostas o seguinte,

Conselheiro 1: Não. O regimento foi lido no dia da criação do conselho e pronto.

Conselheiro 2: Percebo. Porque quando foi feito o regimento, o conselho ele participa. Ele foi feito com todos os segmentos da escola, ele tem, mas ele não tem esse acompanhamento. Eu posso até dizer, afirmar, que o regimento da escola, a gente trabalha muito no início do ano, isso enquanto professora, eu sou conselheira, eu sou representante de professor, a gente faz isso, a gente faz esse trabalho junto com o aluno, mas o conselho como um todo, não está presente neste momento.

Conselheiro 3: Tem, as normas da escola, tem vez que um aluno quer sair, aí chega junto com o conselho, tem chamar um pai ou a mãe pra reunião, sempre.

Conselheiro 4: Os membros que representam professores e funcionários conhecem o regimento escolar, porem os demais, na sua grande maioria não.

Conselheiro 5: Considero que há uma necessidade maior de conhecermos esse importante documento da escola.

Conselheiro 6: Bom, o CE é um órgão colegiado que engloba todos os entes institucionais envolvidos na escola, desde os pais dos alunos, alunos, professores e funcionários. Certo. Nem sempre todos os seus membros, eles dominam uma certa interpretação, um certo conhecimento pedagógico, financeiro-administrativo, apesar de serem pessoas bem intencionadas, a gente nota uma falta de conhecimento técnico.

Conselheiro 7: Apresenta um conhecimento razoável.

Conselheiro 8: Percebo que não tem.

Conselheiro 9: Sempre no início do ano, estudamos os regimento escolar.

Conselheiro 10: A gente trabalha na primeira semana de aula. Quando os professores trabalham os direitos e deveres dos alunos. Mas somente esta parte do regimento.

De acordo com os relatos acima, o conhecimento sobre o regimento escolar é superficial, restringindo-se a uma ação no início do ano letivo, limitando-se a cada segmento tomar 
conhecimento de uma parte do documento. No que compete ao Conselho Escolar, fica claro a falta de conhecimento do regimento e portanto, a função que lhe cabe, que é estabelecer normas para o encaminhamento de ações administrativas, pedagógicas e financeiras fica comprometido, uma vez que esta função está atrelada ao regimento da instituição. Ao observar a dinâmica da escola, não se percebe em nenhum espaço a exposição do documento, seja pelas redes sociais, cartazes, banners ou painéis, o que torna evidente a inoperância do Conselho Escolar neste aspecto.

Para confirmar se o conselho conhece e exerce a sua função normativa, foi aplicado o seguinte questionamento, $O$ Conselho Escolar avalia o cumprimento das normas implementadas pela instituição? Os conselheiros responderam,

\footnotetext{
Conselheiro 1: Óbvio que não. A gente nem conhece as normas.

Conselheiro 2: Bom, ele avalia até de uma forma geral. Isso aí já aconteceu, agora, nessa nova gestão ainda não aconteceu. Na gestão anterior, a diretora fazia essa avaliação, chamava, mostrava, já teve da gente ter até algumas ações. Mas, na atual gestão ainda não ocorreu.

Conselheiro 3: De vez em quando, quando tem reunião, quando chega assim um dinheiro pra fazer um serviço na escola, a gente sempre acompanha. Tem aquela reunião que a diretora faz com a gente, pra saber no que gastar esse dinheiro.

Conselheiro 4: Raramente, pois somente o fazem se forem convocados pelo Núcleo Gestor. Conselheiro 5: Penso que avalia, mas sem muito rigor, ou seja, sem critérios bem definidos. Conselheiro 6: Sim. Principalmente as questões administrativas pontuais, apesar de ser uma das competências do CE estudar a questão do regimento interno e todos os documentos legais, disciplinares que tange a unidade escolar, o CE ele se debruça mais em situações pontuais, principalmente em situações que requer uma decisão mais colegiada no viés administrativo.

Conselheiro 7: Não.

Conselheiro 8: Não. Acho que falta interesse.

Conselheiro 9: No decorrer do ano não existe este acompanhamento, porque estamos envolvidos nas tarefas do dia a dia.

Conselheiro 10: Não. A gente sabe algumas coisas porque a diretora e os coordenadores sempre estão falando.
}

De acordo com os relatos, confirma-se que o Conselho Escolar não exerce a sua função normativa, pois os conselheiros, em sua maioria, afirmam que não avaliam o cumprimento das normas contidas no regimento escolar. $\mathrm{O}$ fato de não exercer essa função, tão importante para o estabelecimento de um clima de respeito e harmonia, fragiliza ainda mais a implantação de uma gestão democrática participativa, uma vez que a quebra das regras podem ser constante e o desgaste nas relações são inevitáveis, comprometendo significativamente o sentimento de pertença, essencial para o sucesso da instituição.

A última etapa do ciclo de perguntas realizadas junto ao Conselho Escolar, diz respeito a função fiscalizadora-avaliativa, voltada para o acompanhamento e controle das ações 
desenvolvidas pela escola, principalmente na aplicação dos recursos financeiros. Neste bloco, foram aplicadas três questões, sendo a primeira Com relação à aplicação dos recursos financeiros e definição das prioridades como, o Conselho Escolar encaminha as decisões?

Conselheiro 1: Faz a reunião e o presidente, todos falam, e o presidente fala sobre as prioridades da escola e a gente assina a ata de acordo com o que foi determinado. Já vindo as coisas pré-determinadas.

Conselheiro 2: Bom, é como eu disse anterior. A gente tem com frequência, na necessidade do recurso, a gente é chamado, todo o segmento, família, os que estão na escola, os auxiliares de serviços gerais, todos os representantes. É mostrado toda a planilha, como deve ser gasto esse recurso, mas, também é mostrado quais são os problemas que existem, pra que é destinado esse dinheiro, mas, também a gente sabe, que no momento que ele deve ser aplicado, não dá pra atender. Então, a gente também, todo o conselho vai avaliar o que é mais urgente, o mais necessário pra aplicação. Porque é muito pouco.

Conselheiro 3: Quando chega o recurso pra escola, a gente vai aplicar no que a escola tá precisando mais, aquele objeto, aquele material pra ajeitar a escola, ajeitar uma limpeza, uma pintura.

Conselheiro 4: A Gestão convoca o Conselho Escolar e apresenta as necessidades prioritárias das escola, bem como expõe os recursos disponíveis, cabendo ao Conselho decidir a ordem em que estas prioridades serão atendidas. A reunião é registrada em ata, assinada por todos os presentes e passa a compor o processo de prestação de contas do referido recurso.

Conselheiro 5: Durante a reunião, são evidenciadas a aplicação dos recursos financeiros, apresentadas e analisadas as prioridades, depois se chega a um consenso, sendo registrada em ata para tomada de decisões.

Conselheiro 6: As decisões são tomadas em colegiado, onde a gente se debruça sobre a questão da dotação que foi alocada por diversas fontes financeiras que são transferidas via Estado, via governo federal. A partir daí, dessa dotação, dessa estimativa de despesas, que a gente analisando a dotação orçamentária, a gente traça as diretrizes prioritárias, tomadas em decisões coletivas, com os membros, para a gente encaminhar essa lista de prioridades. Conselheiro 7: Procura-se direcionar os recursos ao que tem maior prioridade, e ao que apresenta alto custo financeiro.

Conselheiro 8: Sugerimos quais são as prioridades e as decisões são tomadas.

Conselheiro 9: Quando o recurso chega, a direção convoca os conselheiros e apresenta as diversas necessidades da escola, discutimos e elencamos as prioridades para a aplicação dos recursos. Mas, nem todos os conselheiros participam.

Conselheiro 10: A diretora chama os conselheiros, fala do que a escola precisa e depois a gente define o que é mais importante.

A aplicação dos recursos financeiros da escola, por parte do núcleo gestor e Conselho Escolar, é estabelecido pelo princípio da autonomia financeira, citado pela Lei de Diretrizes e Bases da Educação nº 9694/96, que possibilita à escolar definir as prioridades e destinar recursos para saná-las.

"Autonomia financeira refere-se à existência e à utilização de recursos financeiros
capazes de dar à instituição educativa condição de funcionamento efetivo. A dimensão
financeira da autonomia vincula-se à existência de ajuste de recursos financeiros para
que a escola possa efetivar seus planos e projetos, podendo ser total ou parcial. É total
quando à escola é dada a responsabilidade de administrar todos os recursos a ela
repassados pelo poder público, e é parcial quando a escola tem a incumbência de
administrar apenas parte dos recursos destinados, ficando ao órgão central do sistema
educativo a responsabilidade pela gestão de pessoal e as despesas de capital." 
PROGRAMA NACIONAL DE FORTALECIMENTO DOS CONSELHOS ESCOLARES-CADERNO 7, 2004, pp. 84.

No aspecto fiscalizador atribuído ao Conselho Escolar, verifica-se que há uma unanimidade nos depoimentos. Primeiro, o cuidado do núcleo gestor em cumprir com a obrigatoriedade da aplicação dos recursos financeiros pelas vias legais, convocando os conselheiros para a tomada de decisão. Segundo, segue-se um roteiro nas reuniões, em que o diretor expõe as prioridades da instituição e em seguida os conselheiros votam em que será aplicado o recurso recebido. Mas, também pode-se observar que em comparação com as outras funções, apenas esta, se aplica com mais regularidade, restringindo drasticamente o papel desse colegiado.

Outro ponto observável refere-se a frequência das reuniões do Conselho Escolar. Pelo que se pode analisar na fala dos entrevistados, o conselho se reúne apenas quando convocados pela direção da escola e com mais frequência quando chega recursos na instituição, fora este fato, não há reuniões. Fica evidente a falta de ação do colegiado pois, este segundo as orientações da Secretaria de Educação do Estado do Ceará deve e reunir regularmente para discutir problemas e traçar ações, que venham a auxiliar o núcleo gestor da escola, objetivando o sucesso escolar.

O segundo questionamento neste bloco de perguntas foi, Com relação aos resultados de aprendizagem, o Conselho Escolar acompanha e avalia os resultados internos e externos dos discentes da instituição? Os entrevistados responderam,

Conselheiro 1: Não. Em nada.

Conselheiro 2: Não. Isso nunca ocorreu. Porque não tem esse conhecimento da função, porque assim, eи passei muito tempo no conselho escolar como presidente, a gente não segue totalmente dentro desses padrões, que eu como conselheira, hoje eu tô como representante de professores, a gente nunca sentou pra ter essa avaliação dessa forma. Que por sinal é muito interessante, que poderia ocorrer. Se isso ocorrer, quem sabe poderá haver uma mudança, né.

Conselheiro 3: Acompanha. Quando chega assim, o ENEM a escola faz aquelas provas com os alunos, aí chama os funcionários pra trabalhar junto. Tem vez assim, que o ENEM paga a gente, porque a gente tem que vim, porque a gente faz parte da escola e faz parte do conselho.

Conselheiro 4: Na verdade temos imensa dificuldade em reunir os membros do Conselho Escolar, principalmente os representantes de pais e alunos. Desta forma, temos ciência de que estes não acompanham os resultados internos e menos ainda avaliam estes resultados, sejam eles internos ou externos. Já tivemos em nossa escola outros Conselhos bem mais atuantes e conscientes de seu papel.

Conselheiro 5: Considero que quando os resultados são apresentados há um conhecimento dos membros do Conselho, mas necessitando de que ações sejam mais sistematizadas para acompanhamento e avaliação.

Conselheiro 6: Sim. Como eu já falei, o CE tem o papel pedagógico, financeiro e administrativo. O financeiro-administrativo, é o hoje a seara que a gente tá mais 
compenetrado. O pedagógico é sempre exposto em diversos planejamentos, em diversos encontros. Mas, também a gente tem esse momento no Conselho, pra que a gente mostre de uma forma gráfica, de uma forma simplificada e mais objetiva as evoluções no processo ensino-aprendizagem.

Conselheiro 7: Nunca presenciei um encontro para esta finalidade, mas aparentemente os resultados dos discentes não são acompanhados pelo Conselho, e sim por outras partes e mais internamente que externamente.

Conselheiro 8: Não.

Conselheiro 9: Este acompanhamento fica a cargo da equipe pedagógica e professores. Nunca discutimos esta temática.

Conselheiro 10: Não. Quem faz esse acompanhamento é a direção e os professores.

As questões pedagógicas de uma instituição pode ser comparada ao coração no corpo humano, sem ela não há vida. Portanto, o aspecto mais relevante dentre tantos também importantes, é o pedagógico, pois, é ele que garantirá a aprendizagem e o sucesso efetivo de nossos alunos. O não acompanhamento dos resultados de aprendizagem internos e externos da escola implicarão em repetições de erros e o desgaste de forças em ações improdutivas, que consequentemente trarão a frustação para todos da comunidade educativa. O acompanhamento dos resultados pelo Conselho Escolar é mais uma garantia de que o projeto político-pedagógico será aplicado e avaliado constantemente e que as ações pensadas e destinadas à aprendizagem dos alunos serão eficientes. O que se percebe na fala dos conselheiros é que este acompanhamento é inexistente, dificultando de uma certa forma, o fortalecimento do setor pedagógico, já que a ações são pensadas apenas por professores e coordenadores, sem a percepção dos alunos (principais atingidos pelo processo ensino-aprendizagem), dos pais e funcionários, que também são responsáveis por este processo.

\footnotetext{
"O Conselho Escolar é o órgão consultivo, deliberativo e de mobilização mais importante do processo de gestão democrática na escola. Sua tarefa mais importante é acompanhar o desenvolvimento da prática educativa e, nela, o processo ensinoaprendizagem. Assim, a função do Conselho Escolar é fundamentalmente políticopedagógica. É política, na medida em que estabelece as transformações desejáveis na prática educativa escolar. E é pedagógica, pois indica os mecanismos necessários para que essa transformação realmente aconteça." PROGRAMA DE FORTALECIMENTO DOS CONSELHOS ESCOLARES, CADERNO 2, 2004, pp. 23.
}

Assim, percebe-se que mais do que fiscalizador dos recursos, o Conselho Escolar deve ser pedagógico, pois somente ao exercer essa função haverá a garantia da Gestão Democrática Participativa e a implantação de um sistema de ensino eficiente e eficaz.

Finalizando a entrevista, os conselheiros tiveram que responder à seguinte questão: $\mathbf{O}$ Conselho Escolar acompanha regularmente as prestações de contas da instituição, verificando a aplicabilidade dos recursos financeiros recebidos? 
Conselheiro 1: Não, não, a gente apenas uma vez no ano, se não me engano, tem uma reunião que nos é repassada sobre esta prestação de contas, somente.

Conselheiro 2: Sim. Até parece que o conselho tivesse exclusivamente essa função financeira. No que diz respeito pedagógico, a gente atribui mais ao coordenador pedagógico, aos professores como um todo. Mas, o que diz respeito a gestão financeira, isso aí acontece com frequência.

Conselheiro 3: Acompanha, sempre acompanha esse negócio de compra, Quando compra assim um objeto, o conselho chega lá junto, com todas as equipes vai ver em que esse material chegou pra escola, que tem que gastar o dinheiro.

Conselheiro 4: Com relação a prestação de contas dos recursos financeiros, podemos afirmar que é o único assunto que interessa ao atual presidente, portanto a participação e a fiscalização, neste caso é ativa e atuante.

Conselheiro 5: Sim, há um acompanhamento das prestações de contas em período estabelecidos ou quando surge necessidades para esse fim.

Conselheiro 6: Sim. Porque dentro do próprio instrumental, dentro das próprias prestações de contas, seja do FNDE, seja do Fundeb, seja do PJF e outras fontes, é necessário a assinatura dos membros do Conselho Escolar. Então, de posse de um dossiê documental, onde tem notas fiscais, recibos, encaminhamento de propostas, acervos técnicos, edital de licitação, comprovante de pagamento. O Conselho Escolar tem toda a autonomia pra fazer uma auditoria e também pra fazer as suas intervenções, naquele dossiê de provas que ele chama de prestações de contas.

Conselheiro 7: Regularmente não.

Conselheiro 8: Não. Somente quando somos chamados para novas sugestões. Enfim, tudo é muito bonito na teoria mas, na prática é zero.

Conselheiro 9: Sim. Sempre a direção convoca o conselho e apresenta as prestações de contas para verificação.

Conselheiro 10: Quando tem prestação pra mostrar a diretora convoca o conselho. Mas, as vezes não dá pra comparecer à reunião porque a gente trabalha.

Ao analisar os depoimentos dos conselheiros, confirma-se a certeza de que o mesmo, exerce apenas a função fiscalizadora-avaliativa, preocupando-se única e exclusivamente com a aplicação dos recursos e a sua prestação de contas, ficando de lado os aspectos pedagógicos, essenciais para o bom desempenho da escola. Percebe-se novamente, que sempre as reuniões são convocadas pela direção da escola, deixando bem claro a pouca eficiente do Conselho Escolar da instituição.

\section{Discussão dos Resultados}

Quando se fala em educação para todos, ou seja, ofertar para toda a sociedade um ensino de qualidade, que possibilite igualdade de oportunidades entre todos os cidadãos, independente de classe social, contribuindo para uma sociedade mais justa, é algo recente na história do Brasil. É fato notório que desde a época colonial, que a educação brasileira sempre foi elitista, privilegiando uma minoria e deixando à margem a grande maioria da população. 
Durante muito tempo, a educação brasileira ofereceu um ensino excludente, superficial para as classes menos privilegiadas, limitando-se apenas a escolas de ensino elementar, voltado para a alfabetização, tornando o sonho do ensino superior quase que impossível, uma vez que, cursar uma faculdade exigia recursos financeiros significativos, já que inicialmente estas se encontravam em Portugal e posteriormente, em Salvador e Rio de Janeiro. Assim, somente os filhos dos grandes proprietários de terras tinham a oportunidade de se tornarem "doutores".

A escola pública, ofertada pelo governo federal se intensificou com a elaboração da Lei de Diretrizes e Bases da Educação, que ao longo do tempo sofreu modificações e se democratizou cada vez mais. Mas, até que a primeira Lei de Educação fosse aprovada ocorreram muitas lutas de educadores preocupados com um ensino que atingisse a todos os cidadãos e que fosse de qualidade, pois, somente assim, o país iria alcançar o desenvolvimento desejado. Como exemplo concreto, pode-se citar o Movimento Escolanovista, que propunha uma mudança radical na educação, popularizando o ensino. Este movimento não surtiu efeito imediato mas, deixou plantada a semente que posteriormente germinaria (MARQUES, 2006). Durante todo este período, a participação da sociedade na educação brasileira foi mínima, pois, não estava institucionalizada de fato a democracia no país. Tínhamos um país que se dizia democrático mas, que na prática excluía a maioria do povo dos bens e serviços mais relevantes, como o acesso à educação.

Como o processo educacional não era democrático, a escolha de professores e diretores também não era democrática. As escolhas eram feitas pelos dirigentes políticos, colocando pessoas, muitas vezes despreparadas, para exercer cargos de diretores. Não havia a preocupação com a capacitação daqueles que iriam ocupar cargos para a direção das escolas. Professores, alunos, pais não tinham nenhuma influência nessas escolhas, sendo excluídos totalmente dos assuntos relativos à gestão da escola.

Durante um longo tempo, os diretores foram mais administradores do que gestores, sendo a autoridade máxima no interior das escolas. Todas as decisões estavam centralizadas em suas mãos e ninguém poderia interferir em nada, já que não havia um órgão colegiado que possibilitasse a participação da comunidade educativa (LUCK, 2011). Assim, a participação era nula, provocando uma sensação de impotência em todos, que acabavam acatando as decisões do governo e consequentemente dos diretores, sem haver nenhum questionamento. Essa ausência de participação, fragilizava a qualidade da educação, uma vez que, as mudanças aconteciam de forma muito lenta, excluindo a maioria da sociedade de opinar e contribuir para a melhoria e ampliação do ensino. 
Atualmente, a educação brasileira na forma da lei, está bem diferente do que se conhece do passado. Não se concebe mais uma escola excludente, com uma gestão centralizadora e antidemocrática, o que não quer dizer que este tipo de escola não exista mais.

\footnotetext{
“Art. 14". Os sistemas de ensino definirão as normas da gestão democrática do ensino público na educação básica, de acordo com as suas peculiaridades e conforme os seguintes princípios:

I - participação dos profissionais da educação na elaboração do projeto pedagógico da escola;

II - participação das comunidades escolar e local em conselhos escolares ou equivalentes." LDB n9394/96.

(disponível:http://www.dca.fee.unicamp.br/ leopini/consu/reformauniversitaria/ldb. htm- acessado em 11/10/2014)
}

Infelizmente, o que encontramos é até assustador, mas, é uma realidade alarmante, pois, o número de escolas que mantém uma prática centralizadora, com gestores autocráticos e com práticas excludentes é muito grande. Embora, no discurso se intitulem democráticos, na prática é muito diferente, já que limitam suas ações participativas apenas à formalidade, para cumprirem o que a lei determina, mas na essência não há democracia. A participação é quase nula e não há preocupação com o principal, que é a aprendizagem significativa dos alunos. $\mathrm{O}$ gestor, no caso o diretor, tem um papel fundamental na implementação da gestão democrática participativa na escola. Não basta que o mesmo tenha conhecimento do que a gestão democrática, é preciso que tenha internalizado esse conhecimento e que este se traduza em ações no dia a dia da escola. O diretor deve promover momentos de participação, dando voz e vez a toda a comunidade educativa, gerando um clima de corresponsabilidade entre alunos, professores, pais, funcionários da instituição (LUCK, 2012).

No que se refere à Escola de Ensino Médio Barão de Aracati, a liderança do diretor não está focada na implementação da participação e corresponsabilidade, pois, ficou claro a quase não participação do Conselho Escolar na elaboração e acompanhamento do Projeto Político Pedagógico. Embora, a diretora afirme que o conselho não participa porque não tem conhecimento e não quer participar, não se percebe nenhuma prática concreta liderada pela direção para reverter essa situação. O gestor da escola deve ser um líder incansável na luta por uma escola democratizada, criando espaços de estudo e de participação para toda a comunidade educativa. Dizer que o Conselho Escolar não participa porque não quer, não resolve o problema da ausência dos conselheiros no dia a dia da escola. "Motivar e inspirar as pessoas no seu envolvimento em processos socioeducacionais cada vez mais efetivos, no interior da escola e 
na sua relação com a comunidade” (LUCK, 2012, pp. 108,109), é tarefa da equipe de gestão, que deve manter uma visão clara dos objetivos educacionais, da missão e da visão de futuro que a escola deve atingir, sem nunca desistir diante dos obstáculos e das resistências, que não são poucas, motivando a todos ao seu redor.

O planejamento participativo é essencial para que se estabeleça no interior da escola um clima de solidariedade, um sentimento de pertencimento, que se traduzirá em condutas responsáveis e cuidadosas em relação à escola. O conselho escolar da referida escola, não acompanha os planejamentos pedagógicos dos professores, excluindo-se totalmente da responsabilidade de acompanhar e opinar sobre a escola que está sendo construída para os jovens da cidade de Aracati. Um pai, pode não saber sobre os teóricos da educação, sobre Piaget, Wallon, Edgar Morim, mas, ele sabe que escola deseja para seu filho, quais os seus sonhos e suas expectativas, e esses fatores devem ser levados em consideração ao se discutir que conteúdos, metodologias e instrumentos avaliativos são adequados para os alunos. Ouvir os alunos também é uma ação importante, pois, são eles que recebem aquilo que é planejado por professores e equipe gestora (ANTUNES, 2002). Ao ouvir o que os alunos tem para dizer, suas críticas e sugestões, a escola caminha para um ensino mais humanizado e cria um clima de confiança entre professores, alunos, família e núcleo gestor.

\footnotetext{
"Pais e alunos têm muito a contribuir com a construção de uma escola pública de melhor qualidade. Eles têm muito a contribuir na definição e controle das políticas educacionais adotadas nos municípios e estados. O primeiro grande passo é se predispor a participar. Depois, todos estarão juntos no longo caminho de aprendizagem que será percorrido.” (ANTUNES, 2002, pp. 35).
}

Portanto, o conselho escolar precisa urgentemente, conhecer o Projeto Político Pedagógico da instituição, para apoderar-se de seus objetivos, missão e valores que desejam ser construídos, para a partir daí, ter condições de compreender a dinâmica pedagógica da escola e poder opinar e contribuir para o desenvolvimento de um ensino de qualidade. Mas, para que isso ocorra é preciso que o núcleo gestor, na figura do diretor, promova espaços e momentos permanentes de estudo e participação da comunidade educativa, não apenas do conselho escolar, para que de fato se implante uma gestão democrática e participativa na escola.

Dando continuidade à análise dos resultados obtidos sobre o Conselho Escolar em estudo, no que diz respeito à função consultiva, esta também é superficial, tornando o órgão praticamente um apêndice da gestão da escola. Esta função é extremamente relevante pois, traz legitimidade às ações implantadas pela escola. Quando se fala em legitimidade, não é apenas 
aquela voltada para o cumprimento da lei, mas também, aquela direcionada para a comunidade escolar, que vê claramente a participação de seus representantes, colaborando de forma significativa, junto com o núcleo gestor, para garantir o direitos e zelar pelo cumprimento dos deveres em prol de uma educação de qualidade.

Todas as vezes que o Conselho se reuniu para tomar uma decisão, foi quando convocados pela diretora da instituição. Percebe-se na fala de alguns conselheiros a afirmação de que nunca participaram de tal reunião, o que deixa claro que, em muitas vezes o colegiado não estava completo, sendo formado apenas por uma representação, tornando a participação mínima e restrita a um pequeno grupo. É fato notório que o diretor convoca o colegiado, mas também é claro que a sua insistência em trazer todos para a participação é muito pequena, conformando-se com a colaboração, apenas, de uma pequena parcela. Mais uma vez é preciso ressaltar que o diretor de uma escola, deve ser aquele que acredita e defende a gestão democrática e, portanto, sendo o primeiro a lutar para a sua implantação, sempre promovendo espaços para a participação e o debate. Outro ponto a ressaltar, é a postura do presidente do conselho, que se preocupa apenas com os aspectos referentes ao financeiro, deixando de lado pontos essenciais como, o pedagógico e o administrativo. Esse aspecto, fragiliza o colegiado pois, o presidente também deve ser responsável por promover a participação dos demais conselheiros, e quando este não tem essa preocupação, os resultados são a ausência completa desse órgão na instituição.

\begin{abstract}
“(...)este lugar de participação e decisão precisa ser fortalecido por um esforço continuado de todos que já despertaram para o empoderamento político que ele pode propiciar aos que são educados no espaço escolar. É nesta direção que se deve perseverar. Mesmo não sendo o único caminho possível e viável, a constituição e fortalecimento dos Conselhos Escolares é um caminho potencialmente favorável a esta ruptura paradigmática que está se construindo no Brasil ao longo da sua história." VASCONCELOS, SOARES, MARTINS, AGUIAR, 2013, pp. 50 (ufc, conselho escolar)
\end{abstract}

É urgente que a Escola de Ensino Médio Barão de Aracati fortaleça o seu conselho escolar, enfatizando a luta pela construção de espaços de participação, para que ao longo de um processo de formação permanente, se estabeleça uma prática voltada para a democracia e plena participação de todos da comunidade educativa, tornando real a Gestão Democrática.

Além das funções citadas, outra também deve ser exercida pelo Conselho Escolar, a função normativa, uma vez que juntamente com o núcleo gestor este colegiado contribui para a elaboração de normas, para o direcionamento das ações pedagógicas, de gestão e 
administrativo-financeira da escola. De acordo com as respostas, a maioria dos conselheiros declararam não ter conhecimento pleno do documento principal da instituição, o Regimento Escolar, que traz em seu corpo as normas, os direitos e deveres dos segmentos que compõem a escola, os alunos, professores, funcionários, núcleo gestor, bem como o detalhamento das funções dos ambientes como secretaria, biblioteca, laboratórios e outros. O conhecimento de alguns é superficial, somente no início do ano letivo, em que trabalham apenas os dados referentes ao seu segmento. Ex.: alunos tem acesso aos direitos e deveres que lhes correspondem, os professores com as normas que lhe cabem e assim por diante. Assim, confirma-se que o Conselho Escolar não exerce essa função, por não conhecer os documentos oficiais, deixando de participar da elaboração e acompanhamento das ações mais importantes da escola, colocando toda a responsabilidade nas mãos da direção.

Como colegiado atuante, os conselheiros devem ter o conhecimento de todos os documentos oficiais da escola, regimento escolar, projeto político pedagógico, estatuto dos servidores (para os professores e funcionários), proposta de trabalho do Grêmio Estudantil (para os alunos) e de todos os projetos pedagógicos desenvolvidos pela instituição.

Outra função exercida pelo Conselho Escolar é a fiscalizadora-avaliativa, que traz uma característica de acompanhamento sistemático de todas as ações exercidas pela escola, para propor soluções diante de problemas detectados. De acordo com a entrevista aplicada, a única ação que é acompanhada rigorosamente pelo conselho, é a que se refere à aplicação dos recursos financeiros, deixando de lado os aspectos pedagógicos, como o acompanhamento dos resultados de aprendizagem obtidos pelos alunos nas avaliações externas e internas, que traduzem de forma explícita em que nível de aprendizagem a escola se encontra em comparação com outras instituições da cidade, do estado e do país (MARQUES, 2011). A falta de conhecimento dessas informações, fragiliza a aplicação dos recursos financeiros, pois, podem atribuir como prioridades aspectos não pedagógicos, destinando os recursos para ações que não atenderão às necessidades reais da escola. Ter o conhecimento pleno de todos os aspectos que compõem a escola é essencial para que os conselheiros possam exercer suas funções de forma satisfatória, colaborando para que a gestão dos recursos financeiros, seja aplicada de maneira eficiente e eficaz.

A avaliação é um aspecto importantíssimo dentro do processo de ensino-aprendizagem, pois, caracteriza-se por ser um elemento central na prática pedagógica, colaborando para a construção do conhecimento. É através do resultado das avaliações, que os professores obterão subsídios fundamentais para diagnosticar e propor intervenções eficazes, para a melhoria da 
aprendizagem dos alunos. Mas, a avaliação isolada não surtirá o efeito desejado. Esta deve traduzir o Projeto Político Pedagógico da escola, em consonância com a metodologia aplicada.

\begin{abstract}
"É importante que o Conselho Escolar entre nessa discussão, considerando que o tempo escolar, o processo ensino-aprendizagem e a avaliação não têm um conteúdo abstrato. E como isso pode ser feito? Pondo em relevo as finalidades da escola e do Projeto Político-Pedagógico que norteiam o currículo e as ações pedagógicas. Aspectos do cotidiano escolar que precisam ser problematizados podem ser escolhidos como temas de debates, exposições, palestras, filmes e tantas outras atividades. O importante é que se destaque e se analise a natureza das relações pedagógicas que são vivenciadas na escola por seus diversos segmentos e que contribuem para dar uma determinada feição a essa instituição." PROGRAMA DE FORTALECIMENTO DOS CONSELHOS ESCOLARES, CADERNO 4, 2004, pp. 61,62 .
\end{abstract}

A atuação do Conselho Escolar garante à comunidade escolar o poder de gerir os destinos da escola, discutir, elaborar, planejar, executar e acompanhar o seu projeto político pedagógico e assegurar o ensino público e socialmente referenciado. Infelizmente, o que se detectou na Escola de Ensino Médio Barão de Aracati, foi um conselho que não exerce o seu poder, sendo apenas uma formalidade que a lei exige, cumprindo o mínimo possível e eximindo-se de tarefas extremamente relevantes para a gestão democrática. Muitas foram as fragilidades encontradas, como a falta de conhecimento real de suas funções pelo conselho, a inexistência de encontros mensais dos conselheiros para discussão dos inúmeros aspectos da instituição, a inconsistência do núcleo gestor em criar espaços de participação permanente para a comunidade escolar e a falta de encontros para formação permanente dos conselheiros. Estas fragilidades, comprometem de forma significativa a implantação da Gestão Democrática Participativa na escola, sobrecarregando o núcleo gestor e tirando dos professores, alunos, pais e funcionários a sua responsabilidade pelos assuntos que dizem respeito à escola.

Ao analisar documentos como o Estatuto do Conselho Escolar existente na instituição e elaborado pela mesma, seguindo as determinações da Secretaria de Educação do Estado do Ceará, verificou-se que formalmente a escola mantém-se na legalidade. Este documento traz em seus artigos as competências do Conselho Escolar, deixando claro o que cabe ao colegiado nas funções a ele direcionadas, bem como as diretrizes para a composição do mesmo e suas atribuições.

Ao confrontar o documento oficial com a conduta dos conselheiros, confirma-se o quanto a teoria está longe da prática, pois muito do que está contido no estatuto não se percebe no cotidiano e na fala dos conselheiros, obtidas na aplicação da entrevista. Pode-se citar como 
exemplo o que diz o Estatuto do Conselho Escolar da instituição no Capítulo II - Da Finalidade e Competência, artigo $5^{\circ}$, inciso III "Acompanhar o cotidiano da escola, com ênfase na avaliação dos indicadores de acesso, permanência e sucesso dos alunos", e, inciso VII "Criar e garantir mecanismos de participação da comunidade escolar na elaboração e execução do Projeto Político Pedagógico da Unidade Escolar”, retratando o que diz a lei, mas, na prática mostrando outra realidade. Evidencia-se um Conselho que demonstra claramente não conhecer as suas funções, de não acompanhar o Projeto Político da escola e de não zelar pela aprendizagem dos alunos, uma vez que não conhecem os resultados das avaliações externas e internas da instituição.

Diante dessa situação, a escola corre o risco de tornar-se autocrática em suas ações, estabelecendo metas e encaminhamentos a partir da visão de um pequeno grupo, núcleo gestor e professores, centralizando as decisões e não abrindo espaço para que alunos e pais possam colaborar para a implementação do Projeto Político Pedagógico.

Analisando o Plano de Trabalho do Conselho Escolar, verificou-se poucas ações, nenhuma centrada em questões pedagógicas e fortalecimento da participação da comunidade escolar, com características superficiais e de pouco impacto na escola. O plano totaliza apenas três ações, assim descritas:

“a) Requisitar junto à Seduc (Secretaria de Educação do Estado do Ceará) o desmembramento da merenda escolar em desjejum e lanche ao horário normal, garantindo o custeio para o mesmo se assim necessitar;

b) Momentos de estudo e palestra referentes as diversas fontes de recursos transferidos para a Unidade Executora da EEM Barão de Aracati;

c) Eventos educativos, informativos e/ou transdisciplinares (palestras, reuniões) que enfoquem o uso indevido de equipamentos eletrônicos e seus meios punitivos;" Plano de Trabalho do Conselho Escolar da Escola de Ensino Médio Barão de Aracati.

Com relação à primeira ação, observa-se que o Conselho atribui o baixo rendimento de aprendizagem dos alunos, ao fato de chegarem com fome à escola, necessitando assim, de dois momentos de lanche. Verifica-se que não houve um embasamento científico para se chegar a esta conclusão, sendo esta fruto somente do senso comum, baseado naquilo que os professores percebiam. Neste caso, pode-se arriscar que os educadores, não levaram outras questões em consideração para analisar o baixo rendimento dos alunos, como, defasagem de aprendizagem decorrentes do ensino fundamental, metodologias inadequadas e portanto, ineficazes e, instrumentos avaliativos insuficientes e equivocados, que não dão conta das necessidades reais dos alunos. 
Outro aspecto a ser levado em consideração, diz respeito à segunda ação, que se detém exclusivamente no estudo da aplicação dos recursos financeiros, deixando de lado os assuntos pedagógicos e administrativos, tão importantes quanto o financeiro. Esta ação, confirma o que foi detectado nas entrevistas, caracterizando um conselho em que suas práticas estão voltadas apenas para as funções deliberativa e fiscalizadora-avaliativa, onde o foco central são as aplicações dos recursos financeiros da escola e o acompanhamento das prestações de contas.

Por último, temos uma ação voltada para o esclarecimento dos alunos e pais para o problema do uso indevido e inconsequente dos aparelhos celulares, que segundo análise dos conselheiros influenciam negativamente na aprendizagem dos alunos em sala de aula. $\mathrm{O}$ documento utiliza termos autoritários ao se referir aos meios punitivos sobre o uso dos celulares, ou seja, não levando em consideração a nova era tecnológica que os jovens estão vivendo, sem ao menos questionar a utilização dos aparelhos em prol de uma metodologia mais próxima ao universo de nossa juventude.

Em nenhum momento foi citado no documento, o papel que a família tem em relação ao ensino-aprendizagem dos jovens, bem como esta pode ser esclarecida e preparada para lidar com seus filhos adolescentes. Outro ponto observável, é a exclusão dos professores de qualquer responsabilidade pelo baixo rendimento de aprendizagem dos alunos, levando-se em consideração que, a ação do professor em sala de aula é importantíssima para o sucesso do aluno. Claro que, não se pode atribuir somente aos professores a responsabilidade sobre a aprendizagem dos adolescentes, uma vez que outros fatores também são relevantes, como as lacunas de aprendizagem, as questões sociais (familiares, comportamentais, etc.) e outros. Mas. Também é fato que a escola é o principal espaço para o desenvolvimento e construção do conhecimento, cabendo a todos (inclusive ao Conselho Escolar) a responsabilidade pelo sucesso de nossos alunos.

A necessidade de sanar as deficiências do Conselho Escolar da EEM Barão de Aracati é urgente, várias falhas foram detectadas e precisam ser combatidas para que a participação coletiva se implante definitivamente na escola. A guisa de sugestão, algumas ações podem auxiliar a escola a gerar um clima mais democrático e participativo e estimular o Conselho Escolar a ser mais atuante, como,

- Proporcionar um fórum com a participação de alunos, pais, professores e funcionários, para esclarecer e debater a importância e as funções do conselho escolar; 
- Promover momentos permanentes de estudo com os conselheiros sobre as funções do colegiado e também para tratar dos assuntos pedagógicos da escola, começando pela análise do Projeto Político Pedagógico;

- Tornar visível através de cartazes, redes sociais (site, blog, facebook), os documentos da instituição como, proposta pedagógica, regimento escolar, currículo, para que todos da comunidade educativa possa ter acesso;

- Promover reuniões periódicas com os Conselheiros para acompanhamento das ações pedagógicas e participação nos planejamentos coletivos;

- Divulgar e analisar os resultados internos e externos da escola nas avaliações promovidas pela escola ou Secretaria de Educação do Estado do Ceará (SEDUC);

O importante diante do que foi exposto, é iniciar um processo de intervenção para mudar o quadro de apatia detectado entre a comunidade educativa, em particular o Conselho Escolar. Muitos serão os obstáculos a serem ultrapassados, mas, com a perseverança de todos, é possível construir uma escola diferente, pautada nos princípios da democracia e participação ativa.

\section{Conclusões}

Ao finalizar este estudo, algumas reflexões e apontamentos fazem-se necessários, após uma revisão bibliográfica minuciosa e uma construção da realidade adquirida a partir de dados empíricos, que possibilitaram uma análise imparcial e concreta sobre a atuação do Conselho Escolar da Escola de Ensino Médio Barão de Aracati.

A educação brasileira, ao longo de sua história, caracterizou-se pela exclusão de uma parcela significativa da sociedade ao acesso a um ensino de qualidade, que proporciona-se uma melhoria na qualidade de vida da população mais carente. Durante muito tempo o que se viu foi uma escola para os ricos (elite) e outra para os pobres (marginalizados), esta última em um número muito reduzido, dificultando cada vez mais a continuidade dos estudos de uma grande parcela dos brasileiros.

Embora teoricamente, através das leis (Constituição, Decretos e Leis) estivesse garantido o direito à educação para todos os brasileiros, na prática não era o que acontecia. Por muitos anos, o Brasil se caracterizou como um país de analfabetos, com uma concentração de renda absurda, criando um cenário desolador de diferenças sociais gritantes e sem perspectivas futuras de melhora. 
Com a redemocratização do país, volta ao cenário nacional o discurso da participação. Com as discussões para a Assembleia Constituinte, lutava-se para a elaboração de um conjunto de leis que garantisse a liberdade e os direitos para a população. Na educação as discussões não seriam diferentes. Não se concebia mais um sistema de ensino que excluísse boa parte da população, era necessário garantir uma escola democrática e participativa, onde a sociedade tivesse condições plenas de acompanhar e fiscalizar a construção de uma nova escola para os jovens.

Assim, surge a Gestão Democrática Participativa, fundamentada na Lei de Diretrizes e Bases da Educação, que em seu corpo garante os princípios da democratização como, eleições diretas para diretores, a formação de colegiados como os Conselhos Escolares, que em sua composição estabelecem a participação de representantes da comunidade educativa, garantindo o princípio da autonomia para as escolas.

A presente pesquisa realizada na Escola de Ensino Médio Barão de Aracati, possibilitou verificar a atuação do Conselho Escolar e observar como esse colegiado exerce as suas funções.

A partir de informações obtidas após a aplicação de entrevistas com os conselheiros, análise do livro de atas das reuniões e documentos oficiais como Plano de Trabalho do Conselho e Estatuto do Conselho Escolar, foi possível estabelecer comparações entre a teoria e a prática. Teoricamente, alguns conselheiros, através dos documentos estudados, apresentaram um grau de conhecimento de suas funções, mas, ao confrontar as informações com os resultados das entrevistas, ficou evidente que na prática as ações dos conselheiros são ínfimas, pois, não são atuantes, deixando a direção da escola praticamente sozinha nas tomadas de decisões. Muitos conselheiros demonstraram completa ignorância em relação às suas funções, afirmando nunca terem participado de planejamentos pedagógicos ou de ter conhecimento do Regimento Escolar em sua totalidade. Tal fato deixa alguns questionamentos: Por que existe tanta desinformação por parte do Conselho Escolar da Escola Barão de Aracati? Por que alguns conselheiros afirmam nunca terem participado de reuniões pedagógicas? O que de fato impede a atuação desse colegiado?

Alguns dos questionamentos são possíveis de serem esclarecidos. Primeiramente, observou-se que a direção da escola não oportuniza espaços constantes de participação e discussão dos assuntos pertinentes ao pedagógico, administrativo e outros. Atribuindo a culpa ao presidente do Conselho, que "não se interessa em marcar reuniões".

O presidente do conselho, demonstra claro interesse apenas pelos assuntos financeiros, preocupando-se com as reuniões para a aplicação dos recursos que chegam à escola e com as 
prestações de contas. Isso, fica evidente no plano de trabalho, em que há um ação para estudo sobre as ações financeiras.

Outro aspecto a ser ressaltado, é a ausência de encontros mensais para o fortalecimento do colegiado. Esses encontros são fundamentais para as discussões, análises e debates sobre os mais variados aspectos da escola.

É possível que o Conselho Escolar munido dessa consciência poderá vivenciar experiências novas, apropriando-se de todos os aspectos pertinentes à escola. Para isso, é necessário que todos os conselheiros passem a dar suas contribuições, promovendo momentos de participação, fóruns de debate, encontros de convivência e diálogo sobre o cotidiano da escola. Somente assim, poderemos de fato construir uma escola pública de qualidade para todos os cidadãos.

\section{Referências}

AGUIAR, Wanda Maria J.; OZELLA, Sergio. Apreensão dos sentidos: aprimorando a proposta dos núcleos de significação. Revista Brasileira de Estudos Pedagógicos,Brasília, v. 94, n. 236, p. 299-322, jan./abr. 2013.

ALVES, Cierneide Freitas. MOURA, Karidja Kalliany Carlos de Freitas. A Liderança como Instrumento de Administração na Gestão Educacional. Disponível em: www.fclar.unesp.br. Acesso em 13 agost. 2013.

ANDRADE, Patrícia Santos de; CARDOSO, Telma Abdalla de Oliveira. Prazer e dor na docência: revisão bibliográfica sobre a Síndrome de Burnout. Saude soc., São Paulo, v. 21, n. 1, p. 129-140, Mar. 2012.

ANTUNES, Celso. Vygotsky, quem diria?. Em minha sala de aula. Petrópolis: Vozes,2002. BRASIL.

Constituição Federal

1988. www.senado.gov.br/legislação/const/con1988/...05.../CON1988.pdf: Acesso em 11 agos. 2013.

BRASIL. Programa Nacional de Fortalecimento dos Conselhos Escolares, Ministério da Educação / Secretaria de Educação Básica, Brasília -DF, novembro, 2004.

Brasília: 1996.

Senado Federal. Lei de Diretrizes e Bases da Educação Nacional: nº 9394/96.

CONSELHO ESCOLAR: PROCESSOS, MOBILIZAÇÃO, FORMAÇÃO E TECNOLOGIA /Francisco Herbert Lima Vasconcelos, Swamy de Paula Lima Soares, Cibelle 
Amorim Martins e Cefi sa Maria Sabino Aguiar [organizadores]. - Fortaleza: Edições UFC, 2013

GONDIM, L. M. L. Da Bossa Nova à contemporaneidade: Identificando regras sociais relacionadas ao "ciúme" na música brasileira. Monografia, Departamento de Psicologia, Universidade Federal do Maranhão, São Luís, 2013.

LUCK, Heloísa. A Gestão participativa na escola. 10ª ed. Vozes, 2011, Petrópolis: RJ.

Concepções e processos democráticos de gestão educacional. $8^{\mathrm{a}}$ ed. Vozes, 2012, Petrópolis: RJ.

. Gestão educacional. Uma questão de paradigma. $9^{a}$ ed. Vozes, 2011, Petrópolis:

RJ.

Liderança em Gestão Escolar. $8^{\text {a }}$ ed. Vozes, 2012, Petrópolis: RJ.

MARQUES, Luciana Rosa. A cultura democrática na Gestão da escola pública: um estudo da análise do discurso dos conselheiros escolares. Revista Portuguesa de Educação, 2011, 24(1), pp. 73-93 @ 2011, CIEd - Universidade do Minho.

. Caminhos da democracia nas políticas de descentralização da gestão escolar.

Ensaio: Avaliação das Políticas Públicas para a Educação, Rio de Janeiro, v.14, n.53, p. 507526, out./dez. 2006.

MEDEL, C. R. Projeto político pedagógico: construção e implementação na escola. Campinas: Autores Associados, 2008.

NETO, Antonio Cabral. CASTRO, Alda Maria Duarte Araújo. Gestão escolar em instituições de Ensino Médio: entre a Gestão Democrática e a gerencial. Educ. Soc., Campinas, v. 32, n. 116, p. 745-770, jul.-set. 2011. Disponível em <http://www.cedes.unicamp.br

VASCONCELLOS, M.J.E.de Pensamento sistêmico - o novo paradigma da ciência. (4a ed.) Campinas - SP: Papirus, 2005.

\section{Como citar este artigo (Formato ABNT):}

LIMA, Adriana Pinto; ACOSTA, Juan Pablo Wieschollek. Gestão Democrática Participativa: Estudo de Caso no Conselho Escolar da Escola de Ensino Médio Barão de Aracati no período de 2012 a 2014. Id on Line Rev.Mult. Psic., 2019, vol.13, n.45, p. 818-846. ISSN: 1981-1179.

Recebido: 07/05/2019

Aceito 10/05/2019 